\title{
Reflective practice among nurses working in a teaching hospital: An action research with promising benefits for professional development
}

\author{
Véronique Dubé ${ }^{1}$, Francine Ducharme ${ }^{1,2}$ \\ 1. Faculty of Nursing, Université de Montréal, Montreal, Canada. 2. Research Centre, Institut universitaire de gériatrie de \\ Montréal, Montreal, Canada.
}

Correspondence: Véronique Dubé. Address: Faculty of Nursing, Université de Montréal, Montreal, QC., H3C 3J 7, Canada. Email: veronique.dube.1@umontreal.ca

Received: March 9, 2014

DOI : $10.5430 /$ jnep.v4n8p9
Accepted: April 8, 2014

URL: http://dx.doi.org/10.5430/jnep.v4n8p9

\section{Abstract}

Background/objectives: Education and professional development are becoming major issues for the nursing profession, which must adapt to new knowledge in the field of health and aging. This study aimed at developing, field-testing and evaluating the benefits of a reflective practice intervention with nurses caring for hospitalized elders.

Method: Based on the Theory of Human Caring and on the Model for Structured Reflection, the study was carried out using an action research approach. Upon completing the reflective practice intervention, the nurses were invited to describe the nursing knowledge and skills that they developed, as well as their perception of reflective practice as a means of improving their professional practice. The study was conducted with 22 nurses working in a teaching hospital. The reflective practice intervention comprised eight thematic workshops each lasting 75 minutes, held at intervals of three weeks, combined with assigned readings and individual exercises. Qualitative data were collected through open-ended questionnaires and focus groups. These data were subjected to thematic content analysis.

Results: Results show that nurses developed different skills required in reflective practice, including introspection, open-mindedness, communication and critical analysis. The participants recognized that the reflective practice intervention allowed them to develop empirical, ethical, esthetic, personal and emancipatory knowledge. Moreover, they perceived reflective practice intervention as a means of improving their professional practice as it encouraged breaking established care routines and fostered the integration of best practices.

Conclusion: This study demonstrates the potential of a reflective practice intervention in a clinical setting as a novel professional development approach that valorizes nurses' experiences and allows the introduction of interventions based on best practice guidelines.

\section{Key words}

Reflective practice, Professional development, Educational intervention, Action research 


\section{Introduction}

The aging of the global population requires that considerable adjustments be made to nursing care practices. Over the next 20 years, the proportion of elders will hover around $25 \%$ in many of the developed countries ${ }^{[1]}$. In this regard, numerous care settings in both North America and Europe have decried the lack of continuing education in gerontological nursing care $^{[2]}$.

In this light, professional development becomes a major issue for the nursing profession, which must adapt to new knowledge in the field of health and aging. Encouraged throughout nurse education, it is essential to maintain professional development from the moment new recruits arrive in clinical settings. To this end, employers increasingly have been seeking novel ways to sustain this development among nurses who must deliver care and services based on best practices to an ever-growing aging population in care units. Clients aged 65 and over make up $40 \%$ of the stays in Canadian care units, and these elders are often hospitalized for a longer period of time (9 days for those aged 65 and over compared to 5 days for those under age 65) ${ }^{[3]}$. There is a growing recognition that, when elders are hospitalized, their vulnerability can carry risks of functional decline ${ }^{[4]}$. Yet, nurses have little training on how to provide gerontological nursing care, as only $52 \%$ of Canadian university programs offer a mandatory course on gerontology ${ }^{[5]}$. Very few resources specialized in the field of eldercare are available to support nurses in clinical settings ${ }^{[6]}$. This is why more initiatives are being put forth to improve the care dispensed to hospitalized elders. In particular, medication, mobilization and discharge planning are key aspects that require special attention within case management adapted to elders in hospitals ${ }^{[7]}$.

From this viewpoint, reflective practice is seen by many as a means of fostering professional development with respect to these issues related to the quality of care provided to elders in hospitals ${ }^{[8,9]}$. But what exactly is reflective practice? This concept can be defined as a process of learning and developing through the self-examination of one's professional practice, including the experiences, thoughts, emotions, actions and knowledge that enrich it ${ }^{[10]}$. Based on a review of practical experience in the aim of describing, analyzing, evaluating and learning from it, reflective practice seeks to have a positive impact on the approach used by nurses in different care situations ${ }^{[11]}$.

Various professional orders encourage their members to adopt reflective practice in order to maintain their competence ${ }^{[12,13]}$. The advantage of this practice is that it suits the learning strategies preferred by nurses. Indeed, it appears that nurses prefer to guide their interventions based on their professional experience with patients and their exchanges with colleagues rather than on scientific literature ${ }^{[14]}$. However, although reflective practice seems to be very promising for the professional development of nurses, few studies of this practice have been conducted in a clinical context and, to our knowledge, none has so far focused on eldercare.

\subsection{Literature}

A number of theoretical articles and textbooks have presented the features of reflective practice ${ }^{[11,15-17]}$. According to these, it is grounded in the practice of professionals ${ }^{[18]}$ and based on their experiences as a source of learning ${ }^{[19]}$. It can be expressed orally, for example in discussions with a coach or peers, or in writing ${ }^{[16]}$. Moreover, it requires various individual prerequisites, such as self-awareness, description, critical analysis, synthesis, evaluation, and commitment. In addition, according to Johns, reflective practice allows for the emergence of different types of knowledge, including empirical, ethical, esthetic and personal ${ }^{[9]}$. Indeed, empirical knowledge, which refers to knowledge organized systematically according to theories and rules, is not the only form of knowledge acquisition for nurses ${ }^{[20]}$. Ethical knowledge, which is used to act in the best interest of the patient, esthetic knowledge or the individual way that nurses have of seeing, interpreting and approaching a care situation, and personal knowledge, which is composed of a nurse's values, beliefs, attitudes and emotions, are all equally recognized by reflective practice as sources of knowledge essential and necessary to new learning ${ }^{[9]}$.

More than ever, gerontological nursing requires the use of a diversity of knowledge in order to deal with the complexity of care for hospitalized elders. It appears that reflective practice can be used to shed light on the multiple facets of the care 
delivered to the elderly that are too often considered "simple or basic", but which require extended types of knowledge to meet their needs.

In spite these features, few empirical studies to date have demonstrated the benefits of reflective practice for nurses in terms of acquired skills and knowledge, and professional development. Studies of reflective practice have for the most part been qualitative and exploratory and have mainly been carried out in academic rather than clinical settings. In one of the rare quantitative studies, Duke and Appleton found with 62 student nurses that certain skills were easier to develop (e.g., description) than others (e.g., critical analysis) ${ }^{[21]}$. At the end of a case study undertaken in a clinical setting aimed at evaluating a reflective practice intervention with six dyads composed of a novice nurse and a tutor, Forneris and Peden-McAlpine observed that novice nurses had developed critical thinking abilities. It would appear, then, that reflective practice could be used to develop certain skills necessary for nursing practice ${ }^{[22]}$.

As far as we know, no study has ever explored the different types of knowledge that can be developed through reflective practice. However, some studies have identified the benefits of this practice for nurses in clinical settings. The exploratory study by Page and Meerabeau underscored that, after completing reflective practice training, participants $(\mathrm{n}=15)$ were able to identify clinical issues and areas of improvement regarding their practice while obtaining recognition of their professional expertise ${ }^{[23]}$. Similarly, the majority (78\%) of the 70 nurses who took part in the retrospective survey of Paget, reported having made changes to their practice ${ }^{[24]}$. In these studies, however, very little detail was provided concerning the changes enacted and the aspects of practice that were modified.

\subsection{Objectives of the study}

The objectives of this study were to: 1) develop and field-test a reflective practice intervention with nurses caring for hospitalized elders, and 2) describe the skills and knowledge developed by the nurses over the course of the reflective practice intervention, as well as their perception of reflective practice as a means of improving their professional practice.

\section{Method}

\subsection{Design}

This study was carried out using an action research approach inspired by the spiral developed by Kemmis and McTaggart ${ }^{[25]}$. The spiral is composed of cycles each comprising three stages: 1) planning, 2) action and observation, and 3) reflection. These cycles can be repeated as often as necessary until a problem is adequately resolved by and for participants. In our study, each cycle was repeated four times. At the planning stage, the nurses were asked to take part in thematic workshops on notions concerning reflective practice, medication, mobilization and discharge planning. At these workshops, they were invited to contribute clinical situations of their own with which they had issues and then plan how they might improve their practice. In the action and observation stage, they tried out a novel intervention regarding best care practices as laid out in the scientific literature for each of the themes covered and then observed its effects on patients ${ }^{[26-28]}$. Finally, over the course of the reflection stage, the nurses were invited to look back on the experiment and reflect with the group on the benefits and difficulties of this change in practice (see Table 1). Each cycle feeds into the next, as there was clinical interdependence among the four themes covered. For example, the effects of inappropriate medication on hospitalized elders could have an effect on their mobilization (e.g., increase in the risk of falls) and delaying or compromising discharge planning. Each workshop built on the previous one, thereby allowing nurses to review the clinical situations experienced, the interventions tested and the outcomes of their actions. Figure 1 gives a graphic representation of the process of this intervention according to the four cycles of the Kemmis and McTaggart action research spiral. 
Table 1. General objectives and activities of the reflective practice intervention

\begin{tabular}{|c|c|c|}
\hline & General objectives & Activities \\
\hline \multicolumn{3}{|l|}{ Introduction } \\
\hline Week 1 & $\begin{array}{l}\text { Learning about the Theory of Human Caring and the concepts of reflective } \\
\text { practice }\end{array}$ & $\begin{array}{l}\text { Workshop 1. "Reflective practice or how to learn from work } \\
\text { experiences" }\end{array}$ \\
\hline Weeks 2 and 3 & $\begin{array}{l}\text { Consolidating the concepts of reflective practice. Learning how to find } \\
\text { scientific references. Learning more about aging. }\end{array}$ & $\begin{array}{l}\text { Selected readings } \\
\text { Search for articles on aging }\end{array}$ \\
\hline Week 4 & $\begin{array}{l}\text { Challenging perceptions and knowledge on aging. Discussing care } \\
\text { problems encountered. }\end{array}$ & Workshop 2. “Aging: myth or reality?” \\
\hline \multicolumn{3}{|l|}{ Medication } \\
\hline Weeks 5 and 6 & $\begin{array}{l}\text { Adopting a written structured reflection procedure for describing and } \\
\text { analyzing a clinical experience relating to elder medication. }\end{array}$ & Using a reflective journal \\
\hline Week 7 & $\begin{array}{l}\text { Identifying the problems encountered with elder medication (based on } \\
\text { reflective journals). Discussing best practices. }\end{array}$ & $\begin{array}{l}\text { Workshop 3. "One pill, a tiny granule... the complexity of } \\
\text { medication!” }\end{array}$ \\
\hline Weeks 8 and 9 & $\begin{array}{l}\text { Learning about medication best practices. Expanding your range of } \\
\text { interventions. Observing certain benefits for clients. }\end{array}$ & $\begin{array}{l}\text { Selected readings } \\
\text { Applying a new nursing intervention }\end{array}$ \\
\hline Week 10 & Discussing the interventions tested and results observed. & Workshop 4. “Medication cascade: can I slow it down?” \\
\hline \multicolumn{3}{|l|}{ Mobilization } \\
\hline Weeks 11 and 12 & $\begin{array}{l}\text { Adopting a written structured reflection procedure for delivering and } \\
\text { analyzing a clinical experience regarding elder mobilization. }\end{array}$ & Using a reflective journal \\
\hline Week 13 & $\begin{array}{l}\text { Identifying the problems encountered regarding elder mobilization (based } \\
\text { on reflective journals) and making connections with the clinical situations } \\
\text { related to medication. Discussing best practices. }\end{array}$ & Workshop 5. "Being active is healthy!" \\
\hline Weeks 14 and 15 & $\begin{array}{l}\text { Learning about mobilization best practices. Expanding your range of } \\
\text { interventions. Observing certain benefits for clients. }\end{array}$ & $\begin{array}{l}\text { Selected readings } \\
\text { Applying a new nursing intervention }\end{array}$ \\
\hline Week 16 & Discussing the interventions tested and results observed. & $\begin{array}{l}\text { Workshop 6. "The secret to a long life is staying active, says } \\
\text { Mr. Gilles" }\end{array}$ \\
\hline \multicolumn{3}{|c|}{ Discharge planning } \\
\hline Weeks 17 and 18 & $\begin{array}{l}\text { Adopting a written structured reflection procedure for delivering and } \\
\text { analyzing a clinical experience regarding elder discharge planning. }\end{array}$ & Using a reflective journal \\
\hline Week 19 & $\begin{array}{l}\text { Identifying the problems encountered regarding elder discharge planning } \\
\text { (based on reflective journals) and making connections with the clinical } \\
\text { situations related to medication and mobilization. Discussing best } \\
\text { practices. }\end{array}$ & Workshop 7. "It's better to get old at home" \\
\hline Weeks 20 and 21 & $\begin{array}{l}\text { Learning about discharge planning best practices. Expanding your range of } \\
\text { interventions. Observing certain benefits for clients. }\end{array}$ & $\begin{array}{l}\text { Selected readings } \\
\text { Applying a new nursing intervention }\end{array}$ \\
\hline Week 22 & $\begin{array}{l}\text { Discussing the interventions tested and results observed. Summing up the } \\
\text { discussions had during this reflective practice intervention. }\end{array}$ & Workshop 8. “A well-deserved break...” \\
\hline
\end{tabular}

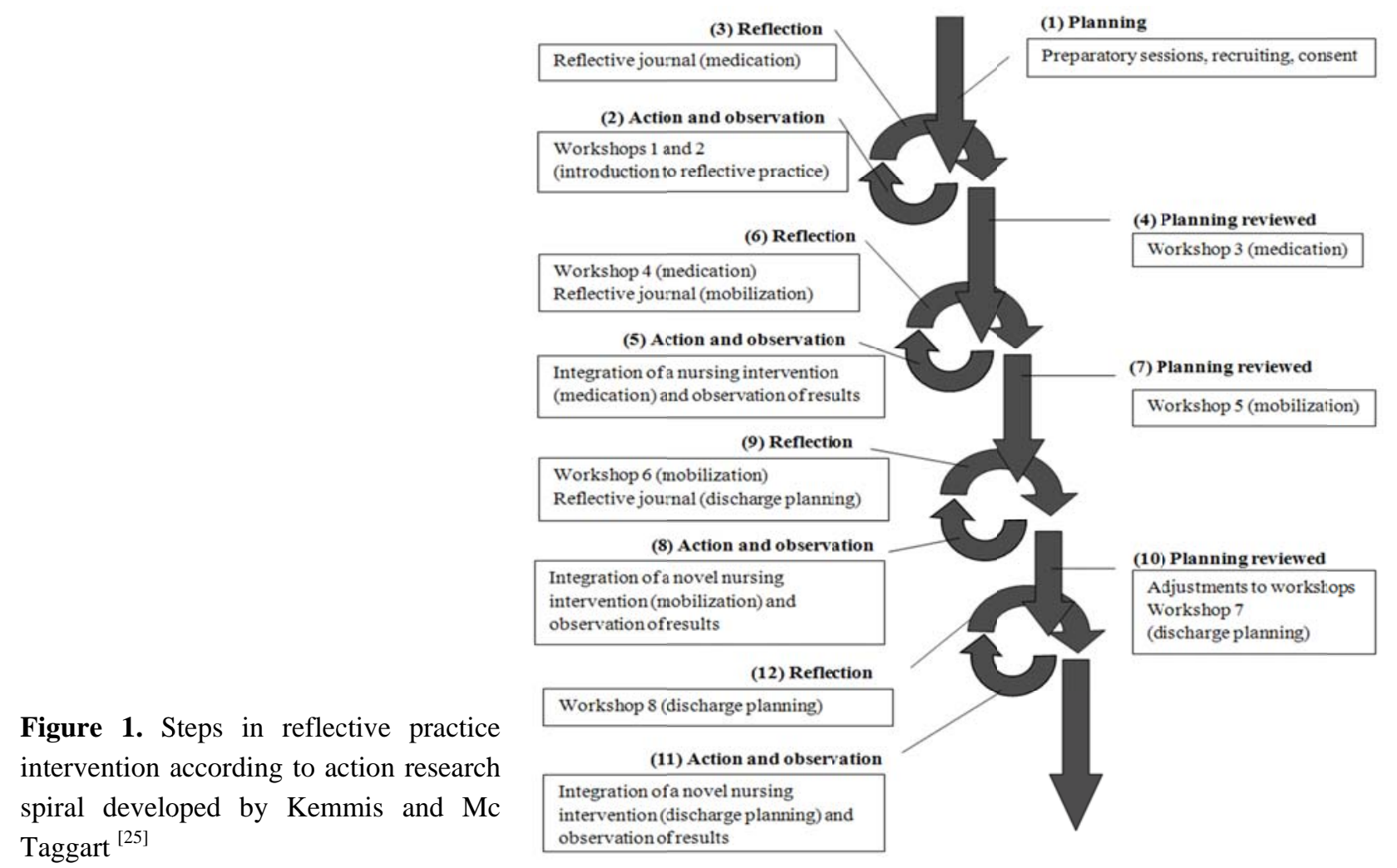




\subsection{Setting, recruiting and sample}

The study was conducted in three medical-surgical care units of a teaching hospital in the province of Quebec (Canada). In the two years prior to the project, between $53 \%$ and $63 \%$ clients admitted to the units were elders. The average age of the hospitalized elders was around 78.7 years and the average stay was 14.4 days. All nurses $(n=75)$ working full or part time on day, evening or night shifts and dispensing care to older patients in these three units were invited to take part in the study on a voluntary basis. A convenience sample of 30 nurses was initially constituted and a total of 22 nurses participated in the reflective practice intervention from start to finish (8 dropouts). The results did not reveal any statistically significant differences in the characteristics of the nurses who took part in the study and those who dropped out. Participants were for the most part women (89\%), had a mean age of 39 years ( $S D=12$ years) and $41 \%$ were university educated. They had 9 years' experience on average ( $S D=11$ years) and worked almost 30 hours per week ( $S D=4$ hours). In our sample, only one nurse had prior exposure to reflective practice in her initial training. Given the sociodemographic data, the nurses in the study sample were slightly younger than the mean age ( $\bar{x}=43.7$ years) of the nursing workforce in Quebec ${ }^{[29]}$.

\subsection{Frame of reference and description of reflective practice intervention}

The reflective practice intervention was developed based on a review of the literature and in accordance with the andragogical principles of reflective and experiential learning that valorize the different types of nursing knowledge ${ }^{[9,16,19,30]}$. Given their complementarity to and consistency with reflective practice, the frame of reference underlying the reflective practice intervention was made up of the Theory of Human Caring developed by Watson ${ }^{\text {[31] }}$ and the Model for Structured Reflection developed by Johns ${ }^{[9]}$. According to the Theory of Human Caring, the purpose of nursing is to help hospitalized elders reach a higher level of harmony across mind, body and soul. We juxtaposed to this theory Johns' Model for Structured Reflection in order to facilitate and systematize the learning of a reflective process. This model is based on the different types of nursing knowledge proposed by Carper ${ }^{[20]}$, namely, empirical, ethical, esthetic and personal, and provides a framework that allows understanding how learning is possible through reflection. This model is particularly well suited to nurses who wish to be initiated to reflective practice, as it serves to guide them through 20 questions that foster reflection. These short, simple questions specify the type of knowledge that they refer to and thus allow nurses to determine the knowledge used or to be developed (e.g.: Did I intervene according to best practices? Did I intervene in the best interest of the patient?)

The nurses followed the reflective practice intervention over a period of 22 weeks. Over the course of this intervention: a) eight reflective practice workshops each 75 minutes long were delivered three weeks apart covering primarily reflective practice, medication, mobilization and discharge planning for elders; b) three reflective journals based on Johns' Model for Structured Reflection were completed by the nurses, one each per selected topic (medication, mobilization, discharge planning), allowing them to describe a recent care situation involving a hospitalized elder and to analyze it using the questions drawn from the Model for Structured Reflection ${ }^{[9]}$; c) three reading assignments on best practices in gerontological nursing care relative to the above-mentioned topics were proposed (one per topic) and; d) three nursing interventions derived from best practices and selected by each nurse were field-tested (one per topic) and followed by a discussion.

\subsection{Data collection and analysis}

Two instruments were used to meet the aims of the study, namely, a questionnaire regarding the nurses' experience of reflective practice (RPQ) and focus groups (FGs). The use of these two instruments allowed us, through the triangulation of the data collected, to capture a wider array of nurses' viewpoints and to discern similarities among them ${ }^{\text {[32] }}$.

Developed by the researchers, the RPQ was completed anonymously by the participants. The questionnaire comprised 11 open-ended questions requiring short answers regarding skills (e.g.: What skills do you think you developed?), types of 
knowledge developed (e.g.: Could you describe in your words what is a reflective practice and what knowledge is needed?), and reflective practice as a means of improving daily practice (e.g.: In your opinion, how can reflective practice help improve nursing practice?) The questionnaire was distributed one week after completion of the workshops.

Two weeks after the last reflective practice workshop, three FGs were held. The aim of these groups was to collect data complementary to that garnered through the RPQ on skills (e.g.: Tell me about the skills you think you developed or strengthened during this project?), knowledge developed (e.g.: What types of knowledge or learning do you think you developed during these workshops?), and reflective practice as a means of improving nursing practice (e.g.: How can the reflective practice workshops be a means of improving nursing practice?). This type of approach has the advantage of obtaining the perspective of many participants in a short period of time and of allowing them to add to, complete or qualify the comments of other participants ${ }^{[33]}$. In all, 11 participants representative of the nurses working each shift took part in these FGs on a voluntary basis. Each FG was composed of three or four nurses and was facilitated by a nurse external to the project, accompanied by an observer.

All the RPQs and the transcripts of the FG recordings were entered via a word-processing application and then imported in the QDA Miner software. Each data set were then subjected to thematic content analysis by the principal investigator according to the approach proposed by Miles and Huberman ${ }^{[34]}$. Specifically, we analyzed the RPQ data based on the 11 questions from the questionnaire. These sections were the main categories or the meta-codes of the analysis: (a) reflective skills; (b) knowledge developed; (c) ways to improve the practice; (d) nursing interventions tried regarding: medication; (e) mobilization; (f) discharge planning; (g) results observed in patients further to the interventions on: medication; (h) mobilization; (i) discharge planning; (j) aspects appreciated; (k) aspects of the reflective practice intervention the least appreciated; (l) ways of improving the intervention; (m) pertinence of the intervention; (n) transferability to other clienteles. We first coded the data segments and then grouped them into theme codes responding to the research questions, namely the reflective skills developed, types of knowledge developed and nurses' perception of reflective practice as a means of improving professional practice. Regarding the FGs, the data were analyzed based on the themes from the group interview guide, namely: (a) overall experience of the reflective practice intervention; (b) skills developed; (c) types of nursing knowledge used; (d) perceived effects of the reflective practice workshops and (e) nurses' perceptions of reflective practice. As with the RPQ, we structured our analysis with meta-codes and thematic codes before extracting a code summary table. An inter-rater agreement was conducted with the co-investigator to ensure the accuracy of the code summary table.

\section{Results}

The results of this study are presented in three sections. The first covers the skills required for reflective practice developed by the nurses over the course of the reflective practice intervention. The second describes the types of nursing knowledge developed during the reflective practice intervention. Finally, the last section presents the nurses' perceptions of reflective practice as a means of developing their professional practice. Excerpts from the transcripts are provided to illustrate each of these sections.

\subsection{Skills required for reflective practice}

One of the objectives of this study was to describe the reflective practice skills developed by the nurses over the course of the reflective practice intervention. Data analysis showed that, following their experiment, most of the nurses who took part in the reflective practice intervention felt that they had a greater capacity for introspection, were more open to new ideas, questioned themselves more often, and were more aware of the acts they performed:

"I think that the starting point is a "greater awareness" of oneself, of others and of one's practice. The fact of reflecting together and sharing, of pooling ideas, leads us to change our way of doing things and reinforces the responsibility we have to provide quality care.” (RPQ\#124) 
For others, the fact of taking a time-out allowed them to improve their skills in communicating with older patients and to enter into a relationship with them:

"It's also a good thing for patients because we stop riding a train going 100 miles an hour. We stop and we say to ourselves: (...) I'm going to take the time to talk to this person and explain what's going on. I'm going to take the time to have a meaningful exchange with the patient.” (FG\#134)

Moreover, some participants reported that they analyzed daily situations better, particularly on account of the fact that they were able to share experiences with a group of peers and to learn differently.

"A lot of our analyzing is done on an individual basis, but what might have helped us here is doing the analyzing in a group. (...) Doing this more systematically, it’s something that could really have an impact on my practice.” (FG\#128)

According to our analysis, most of the nurses seemed to have developed an array of skills over the course of the intervention. In this regard, some were better able to question their practice and demonstrated a greater openness towards new ways of doing things. They tended to take the time to reflect before performing an act instead of carrying out successive tasks automatically. Other participants emphasized that they had improved their communication skills and their capacity for analysis.

\subsection{Types of nursing knowledge}

Another objective of our study was to describe the different type of nursing knowledge (empirical, ethical, esthetic, personal) that nurses felt they had developed following the reflective practice intervention. Some participants reported having broadened their empirical knowledge of the clinical topics covered during the reflective practice intervention. The following excerpt from a FG discussion regarding discharge planning bears witness to this:

"The fact is that we talk about discharge when the time comes to discharge a patient. It comes up at the very end. Instead, the patient's discharge is something we should be planning all along. (...) A lot of progress was made on this thanks to the literature that we were given. There's a lot of new information there.” (FG\#113)

As for ethical knowledge, this is the type that the nurses dwelled on considerably during the reflective practice workshops. It was perceived by some as the knowledge that was most developed during the reflective practice intervention and that led them to question habitual care interventions.

Where personal and esthetic knowledge were concerned, these were also brought up by the nurses but to a lesser extent. One nurse, however, underscored these types of knowledge in particular:

"I became aware that my human kindness is a plus for my patients. It's not a non-professional and pejorative aspect of the nursing vocation. It's through this human kindness that we can convey our knowledge to the patient, to other nurses, to the patient's family.” (FG\#134)

Although our study focused on empirical, ethical, esthetic and personal knowledge, the reflective practice intervention allowed another type of knowledge to emerge: emancipatory knowledge. According to Chinn and Kramer, this refers to knowledge that allows making social and structural changes in order to improve or transform certain aspects experienced by persons with respect to their health ${ }^{[35]}$. Through what certain nurses had to say, we saw this type of knowledge emerge even though it had not been a planned topic of discussion during the reflective practice intervention:

"This way of practising is a way of sharing our knowledge; it could help young nurses as much as more experienced ones. Plus, it would render nurses more aware of the fact that they play a decisive role within the healthcare system!” (RPQ\#134) 


\subsection{Reflective practice as a means of improving professional practice}

One of the objective of our research concerned nurses' perceptions regarding the possibility of reflective practice serving as a means of improving their day-to-day professional practice. A large proportion of the nurses underscored that reflective practice could help improve their practice in different ways. In particular, they mentioned that it could be a means of preventing the routinization of care activities, of avoiding taking ways of doing things for granted, and of looking at situations that they are confronted with from a different perspective:

"It had got to the point that we were doing everything mechanically. That's what happens, we had to hurry up -go, go, go- and so we only did what's essential and we sort of let things slip. But now, we're back on top of things. I want him to get better. He’s going to move. It pushed us to do better.” (FG\#134)

Conducted in group mode, reflective practice led the nurses to reflect upon different care situations, the best ways to intervene, and innovative potential solutions to care issues encountered:

"It's the input of others that is the key to this project. By discussing things together, our colleagues contribute their ideas and offer other ways of approaching a problem and its solutions.” (RPQ\#128)

For a large majority of the participating nurses, reflective practice was a means of improving their practice as it allowed sharing their knowledge and competencies. It was also a way of learning from their peers and staying up to date. Some nurses also mentioned that it involved a dimension of intergenerational learning.

Other nurses pointed out that reflective practice could foster the personalization of care delivered to patients and their families, rendering the nursing intervention more human, conscientious and sensitive:

"We personalize our care more. By doing so, we end up generating way less anxiety. The patients have the impression that they have more control as well.” (FG\#134)

For some nurses, reflective practice also encouraged intervening on the basis of best practices and thus aiming for excellence in care delivery:

"Foster change in care practices by striving for best practices.” (RPQ\#128)

In summary, the nurses described this reflective practice intervention as a means of improving different aspects of their professional practice. In particular, the automatic responses and routines instituted over time were questioned as the intervention allowed stepping back from situations to re-assess them. Thanks to reflection and the sharing of experiences, different perceptions of the same situation emerged, opening the door to different intervention modalities. The fact of pooling the knowledge and competencies of nurses with varying levels of experience was what made this reflective practice intervention a source of learning. Furthermore, this intervention allowed facilitating the personalization of care and encouraged nurses to strive for best care practices.

\section{Discussion}

This study regarding the development, field-testing and qualitative evaluation of reflective practice with nurses who care for hospitalized elders yielded numerous results with potential benefits.

The study targeted nurses working with elders hospitalized in acute care units of a teaching hospital. In light of the sociodemographic data collected, the nurses were in mid-career, a point where a fair number of them were seeking new challenges to meet and opportunities to share their knowledge and experiences ${ }^{[36]}$. This was what this reflective practice intervention had to offer. Moreover, the age range of our sample (23 to 57 years old) allowed meshing older, experienced nurses with newly graduated ones. The heterogeneousness of our sample in terms of age and years of experience thus 
proved a positive factor for this reflective practice intervention, as it allowed highlighting features specific to different generations of nurses.

The action research approach used was particularly well suited to developing and field-testing a reflective practice intervention. Indeed, this approach is consistent with the notion of reflective practice in that it allows the pairing up of researchers and clinicians to co-build different types of knowledge, to share experiences, and to pool ideas in the aim of finding solutions to care issues that they have in common ${ }^{[37]}$. Although the intervention was structured around themes, workshops and exercises to be completed, the nurses were afforded the freedom to choose the angle from which to examine and discuss their clinical experiences as well as the novel nursing interventions to be integrated to their practice.

The nurses reported having developed different skills over the course of the reflective practice intervention, including self-awareness, description, critical analysis, synthesis and evaluation. These are reflexive skills well recognized in the scientific literature ${ }^{[15,21,38]}$. However, our study allowed other less documented skills to emerge as well. In this regard, the nurses mentioned taking a step back before shifting into action. This allowed them to gain a better assessment of situations instead of performing a set string of tasks automatically. The nurses pointed out also having improved their skills in communicating with both the care team and patients. They mentioned that they now conveyed more information to the care team, shared their reflections, and sought the viewpoint of other team members. These improved skills also benefitted the elders, as nurse took more time to communicate with them, gained a better understanding of where patients were at regarding their health situation and, lastly, had genuine interactions.

The development of different types of nursing knowledge was another of the study's concerns. We were able to observe the presence and utilization of these types of knowledge throughout the intervention and to discern the development of emancipatory knowledge. Even though reflective practice as a means of developing empirical knowledge has been little documented in the scientific literature, the nurses in this study mentioned having broadened their scientific knowledge of the three themes discussed over the course of the intervention through the reflective journals, the exchanges, and the readings. Given that research-based data are not among the leading sources of knowledge used by nurses ${ }^{[14]}$, reflective practice seems to be a means that deserves to be promoted in the aim of fostering knowledge transfer and the development of this empirical knowledge.

Less frequently evoked but nevertheless identified, esthetic knowledge and personal knowledge were also part of the types of knowledge developed by the participants. Intuition and relational competencies were reported to be part of the daily practice of nurses. It may be, however, that these two types of knowledge are rarely mentioned explicitly by the nurses working in a teaching hospital because what is valorized above all in those settings is scientific knowledge; tacit and experiential types of knowledge are deemed second class. Benner and Tanner explained that intuition was wrongfully perceived as the basis for irrational acts, for gestures made without thinking, and for knowledge that was unfounded or inspired by the supernatural ${ }^{[39]}$.

Although emancipatory knowledge is not specifically defined under the Model for Structured Reflection ${ }^{[9]}$, it was nevertheless mentioned by some nurses in our study. It appears that the reflective practice intervention was a means of allowing this knowledge not only to be expressed but also to be mobilized. The nurses gained awareness of their power and of their advocacy role.

As already mentioned, various theoretical works in the literature have advanced that reflective practice could serve as a means of improving the professional practice of nurses. However, very few empirical studies have sought to demonstrate this claim. In this study, we explored the viewpoint of nurses regarding the possibility of improving their nursing practice as a result of field-testing the proposed reflective practice intervention. A very large proportion of the participating nurses asserted that it was possible to improve their practice with elders through this intervention. The sharing of experiences and knowledge among nurses of varying ages was mentioned as a means of improving professional practice and a dynamic 
aspect of the intervention. The possibility of quickly putting into practice new learning and reviewing the care results obtained with patients was another concrete means of improving practice and a factor to motivate change.

\section{Limitations of this study}

This study is not without limitations, however, particularly as regards the small size of the sample and the context of the intervention. As a result, caution need to be exercised with respect to the transferability of this reflective practice intervention to other settings.

\section{Conclusion}

This is one of the rare studies to examine a reflective process in a clinical setting. It offers various possibilities for the future development of reflective practice. Though some nursing care teaching facilities already train student nurses to use reflective practice, the practice is not always systematically integrated in the academic curriculum. Yet, early exposure to this type of practice would foster its appropriation by future clinicians and its maintenance throughout their professional career ${ }^{[10]}$. Academic and care settings should undertake a joint reflection process regarding the means to put into place to ensure the development of, transition to and maintenance of reflective practice throughout the professional life of nurses. At a time when innovative means are being sought by care settings to adapt professional practices to new available knowledge, and when traditional continuing education no longer seems to meet the needs of clinicians, certain mechanisms could be put into place by academic and clinical settings jointly to encourage nurses to pursue reflective practice and transmit it to their peers. In sum, in light of the results obtained, reflective practice seems to be an innovative and effective means for nurses to acquire new learning while obtaining recognition for their professional experiences and relying on these to build new types of knowledge. Both academic and clinical settings stand to benefit from embracing this practice in future.

\section{References}

[1] World Health Organization. Ageing and life course. World Health Day 2012 - Good health adds life to years. Retrieved 15 September 2012. Available from: http://www.who.int/ageing/en/index.html

[2] Stone, R. I., \& Barbarotta, L. Caring for an Aging America in the Twenty-First Century. Generations. 2010; 34(4); 5-10.

[3] Canadian Institute for Health Information. Les soins de santé au Canada 2011: Regard sur les personnes âgées et le vieillissement. Ottawa: ICIS, 2011.

[4] Thomas, M.-H. Health care delivery settings and older adults. In S. E. Meiner (Ed.), Gerontologic nursing (4th ed., pp. 148-175). St. Louis, Missouri: Elsvier Mosby, 2011.

[5] Baumbusch, J.L., \& Andrusyszn, M. A. Gerontological content in Canadian baccalaureate nursing programs: Cause for concern? Canadian Journal of Nursing Research. 2002; 34(1): 119-129. PMid:12122768

[6] Thornlow, D. K., Auerhahn, C., \& Stanley, J. A necessity not a luxury: Preparing advanced practice nurses to care for older adults. Journal of Professional Nursing. 2006; 22(2): 116-122. PMid:16564478 http://dx.doi.org/10.1016/j.profnurs.2006.01.015

[7] Doiron, A., \& Dupras, A. Comment survivre à son hospitalisation? Le médecin du Québec. 2009; 44(1): 51-57.

[8] Gustafsson, C., \& Fagerberg, I. Reflection, the way to professional development? Journal of Clinical Nursing. 2004; 13(3): 271-280. http://dx.doi.org/10.1046/j.1365-2702.2003.00880.x

[9] Johns, C. Engaging reflection in practice: A narrative approach. Malden, MA: Blackwell Publishing, 2006.

[10] Atkins, S. Developing underlying skills in the move towards reflective practice. In C. Bulman \& S. Schutz (Eds.), Reflective practice in nursing (3rd ed., pp. 25-46). Oxford: Blackwell Publishing, 2004.

[11] Reid, B. "But we're doing it already!" Exploring a response to the concept of reflective practice in order to improve its facilitation. Nurse Education Today. 1993; 13(4): 305-309. http://dx.doi.org/10.1016/0260-6917(93)90058-A

[12] Nursing and Midwifery Council. Standards to support learning and assessment in practice. NMC standards for mentors, practice teachers and teachers. London: NMC, 2006.

[13] College of Nurses of Ontario. Quality assurance. Reflective practice, 2005. Aavailable from: http://www.cno.org/docs/qa/44008_fsRefprac.pdf 
[14] Estabrooks, C. A., Chong, H., Brigidear, K., \& Profetto-McGrath, J. Profiling Canadian nurses' preferred knowledge sources for clinical practice. Canadian Journal of Nursing Research. 2005; 37(2): 118-141. PMid:16092784

[15] Atkins, S., \& Murphy, K. Reflection: A review of the literature. Journal of Advanced Nursing. 1993; 18(8): $1188-1192$. http://dx.doi.org/10.1046/j.1365-2648.1993.18081188.x

[16] Bulman, C., \& Schutz, S. Reflective practice in nursing (5th ed.).Oxford: Wiley-Blackwell, 2013.

[17] Johns, C. The value of reflective practice for nursing. Journal of Clinical Nursing. 1995; 4(1): 23-30. http://dx.doi.org/10.1111/j.1365-2702.1995.tb00006.x

[18] Schön, D. A. The reflective practitioner: How professionals think in action. New York, NY: Basic Books, 1983.

[19] Boud, D., Keogh, R., \& Walker, D. Reflection: Turning experience into learning. London: Kogan Page, 1985.

[20] Carper, B. Fundamental patterns of knowing in nursing. Advances in Nursing Science. 1978; 1(1): 13-23. http://dx.doi.org/10.1097/00012272-197810000-00004

[21] Duke, S., \& Appleton, J. The use of reflection in a palliative care programme: A quantitative study of the development of reflective skills over an academic year. Journal of Advanced Nursing. 2000; 32(6): 1557-1568. http://dx.doi.org/10.1046/j.1365-2648.2000.01604.x

[22] Forneris, S. G., \& Peden-McAlpine, C. Evaluation of a reflective learning intervention to improve critical thinking in novice nurses. Journal of Advanced Nursing. 2007; 57(4): 410-421. http://dx.doi.org/10.1111/j.1365-2648.2007.04120.x

[23] Page, S., \& Meerabeau, L. Achieving change through reflective practice: Closing the loop. Nurse Education Today. 2000; 20(5): 365-372. http://dx.doi.org/10.1054/nedt.2000.0430

[24] Paget, T. Reflective practice and clinical outcomes: Practitioners' views on how reflective practice has influenced their clinical practice. Journal of Clinical Nursing. 2001; 10(2): 204-214. http://dx.doi.org/10.1111/j.1365-2702.2001.00482.x

[25] Kemmis, S., \& McTaggart, R. The action research planner. Geelong, Australia: Deakin University, 1988.

[26] Gray-Miceli, D. Preventing falls in acute care. In E. Capezuti, D. Zwicker, M. D. Mezey, T. T. Fulmer, D. Gray-Miceli, \& M. Kluger (Eds.), Evidence-based geriatric nursing protocols for best practice (3rd ed., pp. 161-198), 2008. New York, NY: Springer Publishing Company.

[27] Zwicker, D., \& Fulmer, T. T. Reducing adverse drug events. In E. Capezuti, D. Zwicker, M. D. Mezey, T. T. Fulmer, D. Gray-Miceli, \& M. Kluger (Eds.), Evidence-based geriatric nursing protocols for best practice (3rd ed., pp. 257-308). New York, NY: Springer Publishing Company, 2008.

[28] Zwicker, D., \& Picariello, G. Discharge planning for the older adult. In M. D. Mezey, T. T. Fulmer, I. Abraham, \& D. Zwicker (Eds.), Geriatric nursing protocols for best practice (2nd ed., pp. 292-316). New York, NY: Springer Publishing Company, 2003.

[29] Ordre des infirmières et infirmiers du Québec. (2011). Rapport statistique sur l'effectif infirmier 2010-2011 (p.177). Montréal: OIIQ.

[30] McGrath, D., \& Higgins, A. Implementing and evaluating reflective practice group sessions. Nurse Education in Practice. 2006; 6(3): 175-181. http://dx.doi.org/10.1016/j.nepr.2005.10.003

[31] Watson, J. Nursing: The philosophy and science of caring. Boston, MA: Little Brown, 1979.

[32] Denzin, N. K., \& Lincoln, Y. S. (2008). Collecting and interpreting qualitative materials (3rd ed.). Los Angeles, CA: Sage Publications. PMid:19019088

[33] Loiselle, C. G., Profetto-McGrath, J., Polit, D. F., \& Beck, C. T. (2007). Canadian essentials of nursing research. (2nd ed.). Philadelphia, PA: Lippincott Williams\& Wilkins.

[34] Miles, M. B., \& Huberman, A. M. Analyse des données qualitatives (2nd ed.) [Qualitative data analysis]. Paris: De Boeck Université, 2003.

[35] Chinn, P. L., \& Kramer, M. K. Integrated theory and knowledge development in nursing (8th ed.). St. Louis, MO: Mosby Elsevier, 2011.

[36] Armstrong-Stassen, M., \& Ursel, N. D. Perceived organizational support, career satisfaction, and the retention of older workers. Journal of Occupational and Organizational Psychology. 2009; 82(1): 201-220. http://dx.doi.org/10.1348/096317908X288838

[37] Stringer, E. T. Action research (3rd ed.). Thousand Oaks: CA: Sage Publications, 2007.

[38] Schutz, S. Reflection and reflective practice. Community Practitioner. 2007; 80(9): 26-29. PMid:17900024

[39] Benner, P., \& Tanner, C. Clinical judgment: How expert nurses use intuition. American Journal of Nursing. 1987; 87(1): 23-31. http://dx.doi.org/10.1097/00000446-198701000-00012 